By applying percutaneous interventional methods precluding sternotomy, thoracotomy, and cardiopulmonary bypass, it seems possible to reduce mortality and morbidity in a highly selected patient group with aortic pathologic conditions. ${ }^{4}$ Potential complications of catheter-based interventions are evident.

Another interesting side aspect is the documentation of progression of the disease process from a localized aortic tear with an extensive intramural hematoma to a full-blown aortic dissection within 24 hours, as documented by three imaging techniques. The early result in our case is very encouraging, and the CT scan confirmed achievement of the hemodynamic and anatomic goals associated with successful conventional surgical repair. The durability of stent-graft repair remains to be proven. Further application in highly selected patients seems warranted.

\section{References}

1. Dake MD, Kato N, Mitchell RS, Semba CP, Razavi MK, Shimono T, et al. Endovascular stent-graft placement for the treatment of acute aortic dissection. $N$ Engl J Med. 1999;340:1546-52.

2. Grabenwoger M, Fleck T, Czerny M, Hutschala D, Ehrlich M, Schoder M, et al. Endovascular stent graft placement in patients with acute thoracic aortic syndromes. Eur J Cardiothorac Surg. 2003;23: 788-93.

3. Ishihara H, Uchida N, Yamasaki C, Sakashita M, Kanou M. Extensive primary repair of the thoracic aorta in Stanford type A acute aortic dissection by means of a synthetic vascular graft with a self-expandable stent. J Thorac Cardiovasc Surg. 2002;123:1035-40.

4. Nienaber CA, Fattori R, Lund G, Dieckmann C, Wolf W, von Kodolitsch Y, et al. Nonsurgical reconstruction of thoracic aortic dissection by stent-graft placement. $N$ Engl J Med. 1999;340:1539-45.

\title{
The dilemma of skeletonized internal thoracic artery sequential bypass versus proximal pedicled in situ internal thoracic artery plus coronary-coronary free internal thoracic artery bypass for multiple lesions of the left anterior descending coronary artery
}

Duško G. Nežić, MD, PhD, FETCS, Aleksandar M. Knežević, MD, BCh, Milan V. Ćirković, MD, Vojislava Č. Nešković, MD, DEAA, Petar M. Vuković, MD, and Aleksandar N. Nešković, MD, $\mathrm{PhD}, \mathrm{FACC}, \mathrm{FESC}$, Belgrade, Serbia and Montenegro

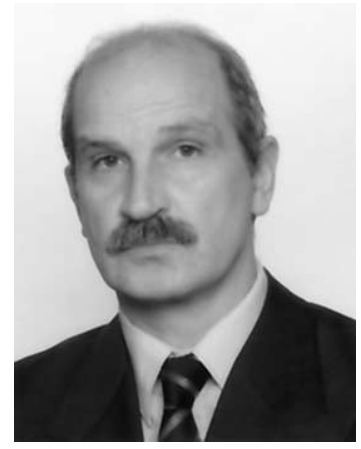

Dr Nežić
$\mathrm{W}$ e describe a case in which the patient's large left anterior descending coronary artery (LAD) had proximal and distal stenosis. We speculated that a pedicled internal thoracic artery (ITA) graft would not have enough length for sequential bypass. Although the effects of skeletonization of the ITA on its long-term patency has not been established, we decided to use a free, short segment of pedicled left ITA as coronary-coronary bypass over a distal lesion on the LAD. The proximal remnant of left ITA was used as an in situ graft to bypass the proximal stenosis on the LAD. In our opinion, this technique may occasionally be an attractive approach when pedi-

\footnotetext{
From the Department of Cardiac Surgery, Dedinje Cardiovascular Institute, Belgrade, Serbia and Montenegro.

Received for publication Nov 24, 2003; accepted for publication Dec 16, 2003.

Address for reprints: Duško G. Nežić, MD, PhD, FETCS, Chief, Department of Cardiac Surgery, Dedinje Cardiovascular Institute, M. Tepića 1, 11040 Belgrade, Serbia and Montenegro (E-mail: nezic@EUnet.yu).

J Thorac Cardiovasc Surg 2004;127:1810-2

$0022-5223 / \$ 30.00$

Copyright $\odot 2004$ by The American Association for Thoracic Surgery

doi:10.1016/j.jtcvs.2003.12.020
}

cled ITA is not long enough to be used for sequential bypass grafting.

\section{Clinical Summary}

A 61-year-old man was admitted with progressive angina (New York Heart Association functional class III on admission). Hypertension, smoking, hypercholesterolemia, diabetes mellitus, and family history were all risk factors for coronary artery disease. Cardiac catheterization and angiocardiography revealed good left ventricular function (ejection fraction 0.60 ) with severe doublevessel disease. There was stenosis $(80 \%)$ in the mid third of the right coronary artery, $70 \%$ stenosis of the proximal LAD, and long ( $3 \mathrm{~cm}$ in length) stenosis as great as $85 \%$ on the border zone between mid and distal thirds of the large LAD (Figure 1).

Bypass surgery with pedicled left ITA and vein graft was planned and accomplished. Vein graft was used to bypass the right system lesion. Because there were two stenoses on the LAD, we decided to use a short, free segment of the left ITA to perform a coronary-coronary bypass (proximal and distal connections were done as terminolateral anastomosis) over the distal stenosis. We also used the remnant of in situ left ITA to bypass the proximal LAD stenosis. The aortic crossclamp time was 43 minutes.

The patient's postoperative course and convalescence progressed without any difficulty, and he was discharged with no angina. A predischarge check angiogram done on ninth postoper- 


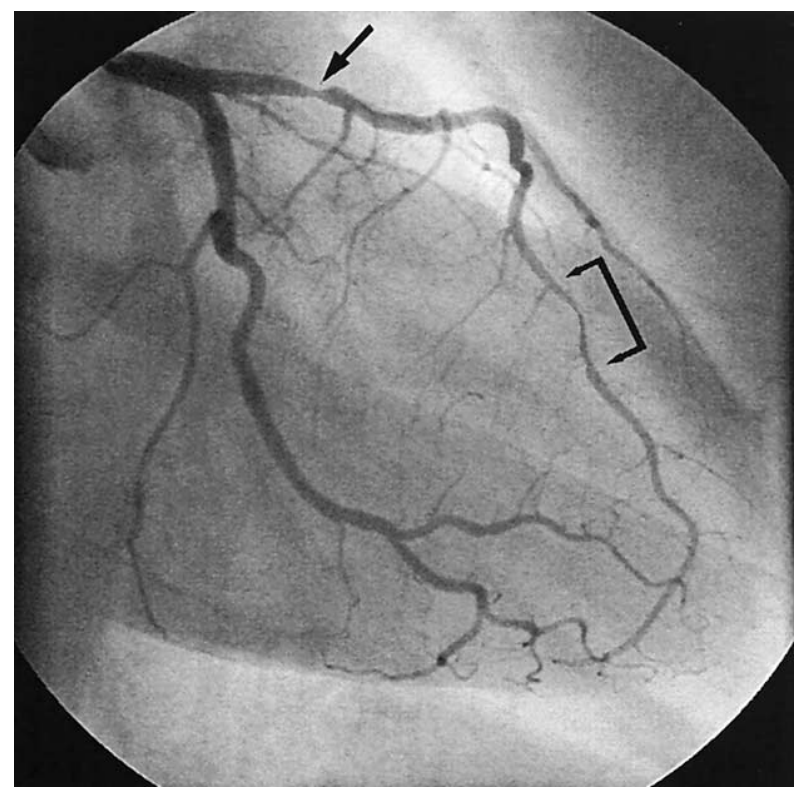

Figure 1. Preoperative angiogram shows proximal LAD stenosis $(70 \%$, arrow) and 3-cm long stenosis (as great as $80 \%$ ) between mid and distal thirds of large LAD (double arrow).

ative day showed patency of the in situ left ITA graft and the coronary-coronary free ITA graft over the distal stenosis on the LAD (Figure 2). The patient has been receiving regular follow-up for 3 months and is in New York Heart Association class I.

\section{Discussion}

The pedicled ITA graft is the criterion standard conduit for coronary artery bypass surgery, with its superiority as a direct result of its high resistance to atherosclerosis. ${ }^{1}$ A 20 -year follow-up study with angiographic confirmation in $90 \%$ of survivors demonstrated an $89 \%$ patency rate for pedicled ITA grafts. ${ }^{2}$ Although total arterial myocardial revascularization is gaining popularity, skeletonization of ITA has recently been advocated to increase the number of arterial anastomoses. Additional advantages of skeletonized ITA are increased available graft length for enhanced sequential grafting, greater blood flow in the early postoperative period, and preservation of collateral blood flow to the sternum. ${ }^{1,3}$ Nonetheless, skeletonization of the ITA may induce mechanical and physical damage to the vessel wall, loss of the vasa vasorum (which may cause ischemia in the outer layer of the media), and loss of draining vein and lymphatic capillaries, which may induce stasis end edema in the vessel wall as well as accumulation of metabolism waste products. Development of significant atherosclerotic lesions secondary to these waste deposits may not be detected for years. ${ }^{1}$ Theoretically, skeletonization of the ITA might adversely affect its long-term resistance to atherosclerosis and subsequently the patency rate. Calafiore's group ${ }^{4,5}$ reported on this problem in two occasions. Midterm results ${ }^{4}$ showed the same patency rate for both pedicled and skeletonized ITA grafts. However, angiographic follow-up was obtained for $15.8 \%$ of patients with skeletonized ITA conduits (133 of 842), with a mean of only $7.6 \pm 2.3$ months for this group. Long-term ${ }^{5}$ patency rate of

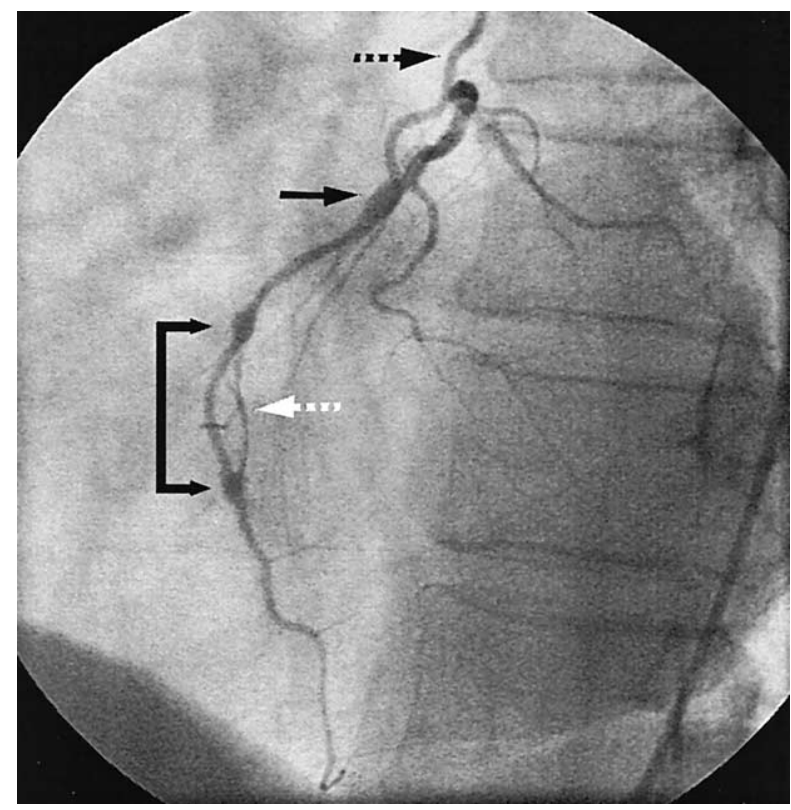

Figure 2. Postoperative angiogram in same patient (left anterior oblique view) shows proximal in situ remnant of left ITA (black dotted arrow) anastomosed to LAD (black arrow) and, distally, patent coronary-coronary free ITA graft (double arrow). Distal stenosis on native LAD is marked with white dotted arrow.

skeletonized ITA was reported to be greater than $99 \%$, but angiographic control was limited to $5 \%$ of the patients (88 of 1737 survivors, follow-up $33.4 \pm 24.7$ months) at a mean of only 17.5 \pm 18.4 months. Because there are long-term studies of pedicled ITA patency at 15 to 20 years available, and available studies of skeletonized ITA long-term patency are not conclusive enough, we consider the effect of skeletonization on long-term patency of the ITA graft has not yet been established.

In our case there were two stenoses (one proximal and one very distal) on the large LAD, running well over the cardiac apex. We usually hesitate to use skeletonized ITA because of our previously mentioned doubts. Although pedicled left ITA graft is sometimes too short to perform sequential bypass in cases of distal stenosis on the LAD, we used a free, short segment of pedicled left ITA for coronary-coronary bypass grafting over that distal LAD stenosis. Biglioli and colleagues ${ }^{6}$ have confirmed the physiologic restoration of coronary blood flow after coronary-coronary bypass grafting. Furthermore, progression of coronary disease at the site of proximal anastomosis (the most critical point of this technique) has never been observed in the largest series (143 patients, total of 148 coronary-coronary grafts) of coronary-coronary bypass grafting (Nottin and coworkers ${ }^{7}$ with a maximum follow-up of 7 years). The in situ remnant of left pedicled ITA was used to bypass the proximal LAD stenosis. A few cases have been reported with the same approach to the problem of double LAD stenosis. ${ }^{8}$ In that series, only 2 of 6 patients underwent follow-up angiography (3 and 8 years after surgery), and ITA grafts were patent (in situ as well as on coronary-coronary position). 
We strongly believe that this technique may occasionally be an attractive approach when pedicled ITA is not long enough to be used for sequential bypass grafting.

\section{References}

1. Del Campo C. Pedicled or skeletonized? A review of the internal thoracic artery graft. Texas Heart Inst J. 2003;30:170-5.

2. Voutilainen SM, Jarvinen AA, Verkkala KA, Keto PE, Heikkinen LO, Voutilainen PE, et al. Angiographic 20-year follow-up of 61 consecutive patients with internal thoracic artery grafts. Ann Surg. 1999;229: 154-8.

3. Ueda T, Taniguchi S, Kawata T, Mizuguchi K, Nakajima M, Yoshioka A. Does skeletonization compromise the integrity of internal thoracic artery graft? Ann Thorac Surg. 2003;75:1429-33.
4. Calafiore AM, Vitolla G, Iaco AL, Fino C, Di Giammarco G, Marchesani $\mathrm{F}$, et al. Bilateral internal mammary artery grafting: midterm results of pedicled versus skeletonized conduits. Ann Thorac Surg. 1999;67:1637-42.

5. Calafiore AM, Contini M, Vitolla G, Di Mauro M, Mazzei V, Teodori $\mathrm{G}$, et al. Bilateral internal thoracic artery grafting: long-term clinical and angiographic results of in situ versus Y grafts. $J$ Thorac Cardiovasc Surg. 2000;120:990-8.

6. Biglioli P, Almanni F, Antona SC, Sala A, Susini G. Coronary-coronary bypass: theoretical basis and techniques. J Cardiovasc Surg. 1987;28: 333-5.

7. Nottin R, Grinda JM, Anidjar S, Folliguet T, Detroux M. Coronarycoronary bypass graft: an arterial conduit-sparing procedure. J Thorac Cardiovasc Surg. 1996;112:1223-30.

8. Barboso G, Rusticali F. Proximal internal mammary in situ graft and distal coronary-coronary graft to revascularize left anterior descending coronary artery. Texas Heart Inst J. 2000;27:70-1.

\title{
Activated recombinant factor VII for refractory bleeding during extracorporeal membrane oxygenation
}

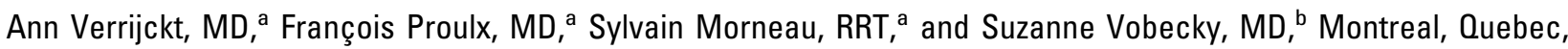 \\ Canada
}

$\mathrm{H}$ emorrhagic complications are a major concern for patients undergoing extracorporeal membrane oxygenation (ECMO) after cardiac surgery. Transfusions of platelets, fresh-frozen plasma and cryoprecipitates are commonly used to improve hemostasis, sometimes in association with antifibrinolytic agents or protease inhibitors.

Activated recombinant factor VII (rFVIIa; Novoseven, Novo Nordisk, Denmark) was originally envisioned for the treatment of bleeding in patients with hemophilia in whom inhibiting antibodies to factor VIII developed. Most recently, rFVIIa has also been successfully used among critically ill patients with impaired thrombin generation and severe hemorrhage after major trauma, liver failure or transplantation, and overdose of oral anticoagulants. We report the case of a child undergoing ECMO with refractory thoracic bleeding, which was controlled by a single dose of rFVIIa $(30 \mu \mathrm{g} / \mathrm{kg})$.

\footnotetext{
From the Department of Pediatrics, Section of Intensive Care Medicine, and the Department of Pediatric Surgery, Section of Cardiovascular Surgery, , Sainte-Justine Hospital, University of Montreal, Montreal, Quebec, Canada.

Received for publication Dec 8, 2003; accepted for publication Dec 24, 2003.

Address for reprints: Ann Verrijckt, MD, Department of Pediatrics, SainteJustine Hospital, 3175 Chemin Côte Sainte-Catherine, Montreal (Quebec), Canada, H3T-1C5 (E-mail: annverrijckt@yahoo.com).

J Thorac Cardiovasc Surg 2004;127:1812-3

$0022-5223 / \$ 30.00$

Copyright $\odot 2004$ by The American Association for Thoracic Surgery

doi:10.1016/j.jtcvs.2003.12.021
}

\section{Clinical Summary}

A term, 3.2-kg male neonate had dextro-transposition of the great arteries diagnosed on the first day after birth. Prostaglandin $\mathrm{E}_{1}$ infusion was started, and a Rashkind atrial septostomy was performed on the second day after birth. The arterial switch operation was postponed until the 12th day of life because of intracerebral hemorrhages with subdural, subarachnoidal, and intraventricular components (diameter $8 \mathrm{~mm}$ ).

The platelet count and coagulogram were within normal limits. Results of screening studies for congenital coagulation factor deficiencies were also normal. Although the child remained free of symptoms and repeated cerebral computed tomography showed a decreased size of the hematoma, he received seizure prophylaxis with phenobarbital. After uneventful anesthetic induction, an arterial switch operation was performed, with ligation of the arterial duct and closure of the atrial septostomy under cardiopulmonary bypass $\left(221\right.$ minutes) with moderate hypothermia $\left(29^{\circ} \mathrm{C}\right)$ and aortic crossclamping (83 minutes). Aprotinin was administered during surgery, followed by protamine during weaning. Abnormal circumflex coronary artery originating from the right coronary artery was felt to be responsible for persistent left ventricular failure, leading to unsuccessful weaning from cardiopulmonary bypass and the requirement for venoarterial ECMO support with a Carmeda coated circuit (Medtronic, Minneapolis, Minn). During the first 2 days, the postoperative phase was characterized by severe bleeding from the chest tubes $(10 \mathrm{~mL} / \mathrm{kg} / \mathrm{h})$, despite massive transfusion of blood products $(7.7 \mathrm{~mL} / \mathrm{kg} / \mathrm{h}$ packed red blood cells, $4.1 \mathrm{~mL} / \mathrm{kg} / \mathrm{h}$ platelets, and $2.6 \mathrm{~mL} / \mathrm{kg} / \mathrm{h}$ fresh-frozen plasma) and calcium chloride.

Surgical reexplorations at 24 and 36 hours after the operation failed to reveal any active surgical bleeding site. Because of persistent hemorrhage from the thoracic chest tubes, aminocaproic 